\title{
Una geopolítica crítica transformada por la pandemia de la Covid-19
}

\section{A critical geopolitics transformed by the Covid-19 pandemic}

\author{
Uma geopolítica crítica transformada pela pandemia da Covid-19 \\ Jaime Antonio Preciado Coronado \\ Universidad de Guadalajara \\ japreco@hotmail.com \\ https://orcid.org/0000-0002-3324-8569
}

\begin{abstract}
RESUMEN
La COVID-19 mostró, sin precedentes, una crisis sanitaria, económica, política y ambiental, alrededor de la cual se comprimió el espacio-tiempo desde una simultaneidad creando un "nosotros" global y sistémico; la pandemia se vive en tiempo real conectado mundialmente, y paradójicamente, fragmentado por las historias nacionales de desigualdad e injusticia social y ambiental. La magnitud de la COVID-19, toma el rol detonante de una nueva geopolítica que trastoca radicalmente el orden mundial, que refuerza al Estado nacional como pivote de la "gubernamentalidad" y que resignifica los poderes locales, particularmente la esfera corporal, de los sentimientos y las emociones subjetivas e intersubjetivas. Donde la incertidumbre y el caos se debaten entre lo viejo que muere y lo vivo que lo reemplaza, estamos ante el (re)surgimiento de imaginarios geopolíticos que actualizan aquella consigna famosa "Otro mundo [de particularismos universalistas, mejor que el actual] es posible".
\end{abstract}

\begin{abstract}
COVID-19 showed, without precedent, a health, economic, political and environmental crisis, around which space-time was compressed from a simultaneity creating a global and systemic "we"; the pandemic is lived in real time globally connected, and paradoxically, fragmented by national histories of inequality and social and environmental injustice. The magnitude of the COVID-19, takes the role of detonator of a new geopolitics that radically disrupts the world order, that reinforces the national state as pivot of the "governmentality" and that resignifies the local powers, particularly the corporal sphere, of subjective and intersubjective feelings and emotions. Where uncertainty and chaos are debated between the old that dies and the living that replaces it, we are before the (re)emergence of geopolitical imaginaries that update that famous slogan "Another world [of universalist particularisms, better than the current one] is possible".
\end{abstract}

\section{RESUMO}

A COVID-19 mostrou, sem precedentes, uma crise sanitária, econômica, política e ambiental, em torno da qual se comprimiu o espaço-tempo desde uma simultaneidade criando um "nós" global e sistêmico; a pandemia se vive em tempo real conectado mundialmente, e paradoxalmente, fragmentado pelas

1 Agradece la colaboración de la P. Lic. En Estudios Políticos y Gobierno, Minerva Araceli Cortés Acevedo en la formulación de este escrito.

\section{Citar como:}

Preciado, J. (2020). Una geopolítica crítica transformada por la pandemia de la Covid-19. Espiral, revista de geografías y ciencias sociales, 2(4), 005 - 021. http://dx.doi.org/10.15381/espiral.v2i4.19529 
histórias nacionais de desigualdade e injustiça social e ambiental. A magnitude da COVID-19, toma o papel detonador de uma nova geopolítica que transtorna radicalmente a ordem mundial, que reforça o Estado nacional como pivô da "governança" e que ressignifica os poderes locais, particularmente a esfera corporal, dos sentimentos e das emoções subjectivas e intersubjectivas. Onde a incerteza e o caos se debatem entre o velho que morre e o vivo que o substitui, estamos ante o (re)surgimento de imaginários geopolíticos que atualizam aquela consigna famosa "Outro mundo [de particularismos universalistas, melhor que o atual] é possível".

PALABRAS CLAVE: Covid-19; Geopolítica critica; América Latina; Desafíos; Estado nacional.

KEYWORDS: Covid-19; Critical Geopolitics; Latin America; Challenges; Nation State.

PALAVRAS CHAVES: Covid-19; Geopolítica critica; América Latina; Desafios; Estado nacional.

\section{Introducción}

En la búsqueda en la web, realizada los primeros días de julio, de las palabras clave: geopolítica + Covid-19 + coronavirus + 2020, encontré 348 mil registros (al 10 de julio en google 5,200,000 resultados, mientras que en Yahoo! 197,000 resultados). Si añadimos la palabra "crítica", el registro baja a 47 mil referencias. Esa misma búsqueda en inglés: geopolitics + Covid-19 + coronavirus + 2020, arrojó apenas 2 mil 840 registros (al 10 de julio en google 1,470,000 resultados y en Yahoo! 39,300 resultados). Contraste que es mayor al consultar: critical + geopolitics + Covid-19 + coronavirus +2020, que únicamente alcanzó 175 referencias (al 10 de julio 1,650,000 resultados en google, mientras que Yahoo! arrojó apenas 91,300 resultados). Intuitivamente se puede señalar que el contraste entre ambas lenguas corresponde a dos culturas narrativas: la incorporación de conceptos multívocos con cierto lirismo y espontaneidad, en el caso del español, o el uso más riguroso de conceptos con tantas implicaciones definitorias de una manera más exigente en el idioma inglés; probablemente en la narrativa anglosajona cuenta más que la geopolítica tiene un origen maldito, como lo señala Heriberto Cairo (1993), lo cual desanima la utilización del concepto geopolítica con mayor frecuencia en la literatura anglosajona.

Lo que no podemos negar es que, tanto en inglés como en español, hay un creciente interés por vincular la aparición de la pandemia de la Covid-19 con el espacio y con el ejercicio del poder en todas sus manifestaciones políticas, sociales, culturales y por supuesto económicas. En los registros obtenidos se puede constatar que las opiniones e investigaciones periodísticas o incluso los análisis académicos, recurren con mayor fluidez y espontaneidad a comprender el juego de escalas que hay entre lo local, lo nacional y lo global.

Particularmente, en esta coyuntura de pandemia hay que reconocer que el coronavirus ha impuesto una centralidad nunca antes vista al Estado nacional, dada la revalorización de la capacidad estatal para controlar los flujos de interconectividad terrestres, aéreos y marítimos, las fronteras nacionales, la movilidad de las personas y muy especialmente el rol de la potencia pública para decretar o administrar estados de excepción o estados de sitio. A este poder de control territorial se une la fuerza del enfoque estadocéntrico, mostrado contundentemente en los rescates financieros avalados y garantizados por los Estados nacionales entre 1995 y 2007-2008. La pandemia de la COVID-19 anuda problemas sanitarios, económicos, políticos y sociales, en los que el Estado fortalecido -"recargado"- cobra mayor protagonismo en la política y las relaciones internacionales. Bajo el coronavirus emergieron las debilidades de las instituciones financieras internacionales, tanto como de las instituciones comunitarias de integración regional, las cuales se mostraron incapaces de ofrecer respuestas globales articuladas frente a una pandemia que es global y local. Ni las Naciones Unidas, ni el G7 ni el G20, logran establecer propuestas coherentes de carácter global y apenas luego de 4 meses de pandemia la Unión Europea ofrece un plan de acción en torno de las finanzas y la cooperación internacional para enfrentar la pandemia. 
Estamos ante una crisis global, causada por el impacto planetario destructor de la naturaleza en torno de las cadenas de valor y por la expansión mundial del régimen de acumulación capitalista; que es también una crisis sistémica que abarca todos los ámbitos de la actividad humana socialmente producidos: la hegemonía neoliberal de la privatización de la esfera pública, la desregulación del poder del Estado, su sesgo hacia la financiarización (socializar las pérdidas, privatizar las ganancias), la difusión de un ideario democrático con pretensiones universalistas, pero reproductor de la dominación patriarcal y la generalización del individualismo consumista utilitarista. Esa crisis multidimensional es agravada por los efectos causados por el coronavirus: la lucha entre imaginarios de vida y el avance mortal del capitalismo conduce a la necropolítica: la decisión sistémica sobre quién y cómo vive y quién muere. Una estructura del biopoder excluyente que, sin embargo, está sujeta a luchas y resistencias sociales que critican las instituciones realmente existentes y que ofrecen respuestas comunitarias frente a esa crisis global y sistémica.

Frente a la COVID-19, cobra mayor importancia la interpretación contextual-relacional del capitalismo, la naturaleza y la sociedad que ofrece la geopolítica. Desde su vertiente clásica, se retoman los principios fundadores para la mejor comprensión de la base geográfica real del poder mundial. Con base en una matriz de interpretación eminentemente estadocéntrica, interestatal, se piensa el orden mundial en una escala planetaria donde está en juego la hegemonía de una potencia y la jerarquización estatal de centros y periferias que somete a los Estados al servicio de la potencia hegemónica. En contraste, la geopolítica crítica actualiza sus debates entre una vertiente posmoderna construida fundamentalmente bajo parámetros anglo-eurocéntricos, y otra que surge desde las epistemologías del Sur Global con una teoría de la complejidad crítica del Sistema Mundo Moderno, desde la colonialidad del poder, el cuestionamiento del patriarcado bajo el enfoque de género, la transformación liberadora y la visibilidad de alternativas.

Esta época de la Covid-19enmarca la crisis global y sistémica, en un tiempo comprimido en la simultaneidad: un nosotros-as que nos hace universales y planetarios en tiempo real, pero que también evidencia la herencia fragmentada que domina el imaginario de comunidad política y de colectividad territorial. Sería prematuro hipotetizar en torno del sentido de transformación que genera esta pandemia; lo que por ahora se puede constatar son los cauces bajo los que se operan diversas transformaciones geopolíticas: la disputa por la hegemonía frente al orden mundial es cambiante e incierta. Unipolaridad y multipolaridad se enfrentan alrededor del multilateralismo y la cooperación internacional, los nacionalismos supremacistas junto con los integrismos religiosos llevan hacia la polarización en todos los órdenes de la vida social. Las instituciones financieras internacionales se debaten entre la ortodoxia monetarista neoliberal y políticas de corte (neo)keynesiano que están sacudiendo las reformas de mercado basadas sobre la austeridad y el control de la macroeconomía, pues el manejo de la pandemia requiere de nuevos enfoques que incluyen al poder de regulación estatal y un entramado novedoso sobre los roles del Estado nacional y las comunidades territoriales locales. En todo ello, la geopolítica crítica tiene grandes potenciales de interpretación, que ya empiezan a desplegarse en lo que pudiéramos nombrar como una comunidad epistemológica, que es transdisciplinaria y que es sensible ante la complejidad de las geografías del poder.

\section{Geopolítica clásica y vertientes de la geopolítica crítica en la interpretación de la crisis global y sistémica}

Desde el enfoque crítico de la geopolítica, se caracterizó la emergencia de una crisis global y sistémica de carácter multidimensional y planetaria, luego que el agrietamiento financiero estadounidense de 2007-2008 sacudió simultáneamente a la economía mundial y las políticas económicas neoliberales, al modelo energético 
basado en las energías fósiles no renovables, al cambio climático y la destrucción de la biodiversidad, a partir de la transformación del espacio geográfico en territorios bajo creciente disputa. Esas megatendencias en crisis afectan todo el andamiaje conceptual con el que interpretamos la totalidad del Sistema Mundo, sus articulaciones con las distintas escalas en las que el poder se ejerce desde lo global hasta lo local, la materialidad de esas articulaciones que valoriza y paralelamente desvaloriza al espacio mediante la localización y la deslocalización de la producción y la adaptación a parámetros vinculados con la división internacional del trabajo dominante.

Simultáneamente, esa globalización de la crisis reconfigura la jerarquía centro periferia entre los sistemas de actores estatales y no estatales, dados los nuevos-viejos roles que cumplen dentro de las relaciones sociales y la estructura del poder capitalista resultante de la lucha entre colonialismo y modernidad, lo cual introduce el tema del racismo, así como entre patriarcado y feminismo, que exige la mirada transversal del enfoque de género, plasmado en diversas geopolíticas feministas que se reclaman como imprescindibles dada la radicalidad de sus críticas frente al capitalismo. Así como la economía política tiene rostro de género, la cuestión socioambiental también demanda una mirada complementaria de la geopolítica crítica. En la cual, la ecología política contribuye a la formulación de un campo problemático que ofrece nexos epistemológicos con la mirada crítica de la geopolítica.

Si bien esa mirada corresponde a la crítica y superación de la geopolítica clásica, la formulación del campo conceptual del enfoque crítico se ha enriquecido luego de que en la década de los 80 surgiera la obra fundadora Critical Geopolitics de Geraoid O'Thuatail (también conocido como Gerard Toal) (1996) quien junto con Simon Dalby (1991), Klaus Dodds (2000), John Agnew (2016), Sanjay Chaturvedi y Timothy Doyle (2015), Joanne P. Sharp (1996), y Paul Routledge (2000), entre otros, adoptan una visión crítica postmoderna. Los debates que contribuyeron para esas formulaciones provienen de la economía política internacional y de la teoría del Sistema Mundo, de la teoría política y de las relaciones internacionales. Se inspiran en la Escuela de Frankfurt y les dan importancia a las narrativas, los discursos -incluyendo los mapasy las prácticas del sistema diferenciado de actores.

Aunque en el Sur Global también se debate el concepto de la geopolítica clásica (Borón, 2012), aquí se opta por distanciarse del enfoque dominante de carácter angloeurocéntrico, pero las teorías geopolíticas abarcan un campo problemático en el que sus fuentes provienen de conceptos y categorías de diversas ciencias sociales, sin que el carácter interdisciplinario adoptado deje ver con claridad, todavía, la construcción de un campo propio de la geopolítica crítica. En esas epistemologías del sur se cruzan dos procedimientos conceptuales: algunos autores incorporan lo geopolítico en su discurso disciplinario (Barrios, 2009); Carlos Pereyra Mele coordina un esfuerzo multimedia: Dossier Geopolítico. Análisis Geopolítico desde Suramérica (https:// dossiergeopolitico.com) el cual ofrece recursos analíticos y documentales originales.

Simultáneamente, empieza a registrarse el trabajo de otros autores y de grupos disciplinarios que centran sus reflexiones en torno del campo crítico específico de la geopolítica, como Ana Esther Ceceña, (2009), que se enfoca en una geopolítica emancipatoria, quien además es fundadora del Observatorio Latinoamericano de Geopolítica (http://geopolitica.iiec.unam.mx), instancia que cuenta con una amplia obra crítica del neoliberalismo y sus megaproyectos, que incluye una colección de mapas muy sugerente. La formación del Centro Estratégico Latinoamericano de Geopolítica (CELAG), se inspira en el progresismo; lo conforman personalidades de la política e intelectuales que optan por esa orientación política. El Grupo de Trabajo: Pensamiento Geográfico Critico Latinoamericano, de CLACSO, produce periódicamente el Boletín Geocrítica Latinoamericana, publicación que ofrece escritos en diálogo con la geopolítica crítica. 
En ese hacer, se ha buscado un diálogo con la teoría crítica de la dependencia y de la colonialidad del poder, que problematizan conceptos como hegemonía, imperialismo, centro-periferia-semiperiferia; la cuestión del racismo, la etnia, la nación y la clase. Igualmente, la crítica al patriarcado y la dominación de género es otro campo dialógico, desde donde se revalorizan las intersubjetividades, las emociones, los sentimientos en su corporalidad. Al igual que la ecología política y los movimientos sociales ambientalistas o de otras vertientes sociopolíticas lo hacen. Surgen así nuevos imaginarios geopolíticos, tales como ecofeminismos (Mies y Shiva, 2016), afrofeminismo (Thiong'O, 2015), o feminismo decolonial (Montanaro, 2017), que nutrirán un rico debate con la geopolítica crítica postmoderna.

La originalidad y fuerza planetaria y multidimensional de la pandemia de la Covid-19 como crisis sanitaria, económica, ambiental, cultural respecto de la convivencia y el conflicto social y personal, público, colectivo e individual, está restituyendo categorías y conceptos claves de la geopolítica crítica en los discursos periodísticos, analíticos, de carácter estratégico y de previsión de políticas públicas, así como en las prácticas de actores estatales y no estatales, que desafían la formulación del campo problemático que ofrece este enfoque. Sobre todo, porque esta pandemia tiene una singularidad que es única en la historia de la humanidad: comprime el tiempo, el espacio y la condición existencial alrededor de la crisis entre Eros y Thanatos. Entre la geopolítica de la vida o la imposición de muerte. Estamos inmersos en una crisis que nos hace universales pero fragmentados en tiempo real. Un espacio-tiempo online que nos impone un desafío que es simple frente a nuestra fragilidad: morir o vivir como cualquier otro ser vivo; pero a la vez complejo: interpretar-nos dentro del conflicto, descubrir las fuentes de las desigualdades sociales, asumir la herencia buena y mala que se concretiza en el Nosotros-as, en nuestra aceptación del Otro-a y de las diferencias en las que convivimos o rechazamos dentro de conflictos que nos separan.

De aquí surge el necesario registro de las transformaciones del pensamiento geopolítico crítico: la revalorización de los aportes conceptuales de este enfoque y, simultáneamente, la actualización teórica que exige esa crisis global, sistémica, multidimensional, planetaria, en la que la crisis sanitaria reclama el protagonismo al retrotraer el pasado, imponer la imaginación prospectiva hacia el futuro y reforzar en el presente la prueba de fuego frente a nuestra precaria existencia como especie humana.

Las líneas maestras de este espacio-tiempo comprimido en la simultaneidad online, sugieren algunos temas donde la geopolítica crítica se está transformando y transforma la pandemia de la Covid-19:

\section{La sopa de Wuhan: un pensamiento geopolítico crítico desde la posmodernidad}

La creación de un pensamiento geopolítico crítico penetra sutilmente al mundo de los intelectuales y expertos, a gobiernos y operadores políticos, repercute en la mediatización informática y en las redes sociales. Con una velocidad impresionante se publican compilaciones que reúnen diálogos interdisciplinarios y transdisciplinarios en torno de la pandemia. Se ha producido una combinación de análisis y de saberes entre las ciencias sociales que se comunica con mayor fluidez, en la medida en que la universalización del mundo obligada por ese desconocido agente mortal del coronavirus, nos fuerza a conversar desde observatorios antes acotados por una mirada autorreferencial.

Además, el diálogo supera la fragmentación disciplinaria al abrirse al conocimiento del campo médico, los tratamientos, la falta de la vacuna, el equipamiento hospitalario, los medicamentos y accesorios vinculados con la enfermedad y la preservación de la 
salud. Este diálogo se conecta irremediablemente con la naturaleza, las ciencias de la tierra, la ecología política, los movimientos socioambientales y la demanda de justicia socioambiental en un marco de equidad, respeto y vigencia de los derechos humanos en toda su expresión multidimensional: económica, política, social, cultural, derechos y poder de la naturaleza.

Algunos ejemplos de la producción intelectual reciente ilustran la convergencia de un pensamiento complejo, que está influido por la visión crítica de la geopolítica: La Sopa de Wuhan (AA. VV., 2020) -desafortunado título que estigmatiza a China, donde se origina el virus, y su cultura alimentaria, por comer murciélagos- ofrece una compilación de trabajos que aparece en marzo de 2020. Aunque entre los destacados autores que participan en esta obra únicamente David Harvey plantea explícitamente un enfoque crítico de la geopolítica, toda la producción intelectual de este libro está influenciada y dialoga directamente con ese campo de conocimiento que vincula espacio y poder.

Las pandemias en la historia atraen una narrativa que es a la vez planetaria, apocalíptica, susceptible frente a la conspiración de las elites del poder y sus objetivos aviesos. Ello despierta imaginarios espaciales que se debaten, como vemos en el texto de Giorgio Agamben, "La invención de una epidemia", y sus manifestaciones objetivas que, sin embargo, dividen a optimistas y pesimistas sobre la agencia humana para controlar el contagio en los espacios en los que se interviene. En el texto, hay posiciones encontradas sobre la singularidad viral de la Covid-19. En el artículo "Excepción viral", Jean Luc Nancy polemiza con Agamben en torno de las diferencias entre otras enfermedades gripales y la Covid-19, pues este nuevo virus mata 30 veces más que las anteriores gripes. "Sobre la situación epidémica" de Alain Badiou, discute los antecedentes relativos a la investigación epidemiológica que, sin una política mundial que recoja aprendizajes, batalla con mayor incertidumbre.

Otro grupo de artículos destaca el impacto del Estado de excepción al que se ven enfrentadas las diversas modalidades de la gestión pública de la epidemia. En las que los sistemas de salud son nacionales y el Estado debe ocuparse de los enfermos dentro de sus fronteras, mientras que la Organización Mundial de la Salud (OMS) plantea una política global para contener la pandemia, como establece "El virus, el sistema letal y algunas pistas...", de Markus Gabriel. Hay metáforas que articulan escalas geopolíticas del coronavirus, que parece ser una forma de dictadura mundial multigubernamental policíaca y militar. De acuerdo con María Galindo en su artículo: "Desobediencia, por tu culpa voy a sobrevivir". Estado de excepción, totalitarismo y democracia se tensionan en el tipo de modulaciones públicas frente a la pandemia; en "Fragilidad y tiranía (humana) en tiempos de pandemia", Gustavo Yáñez-González ve que la biopolítica apunta hacia las propias comunidades, quienes administran colectivamente la salud del cuerpo social, mientras que los gobiernos sólo se limitan a gestionar la muerte. Aquí cobra sentido el lenguaje de la guerra que se ha trasladado al Estado de excepción y al Estado de sitio como legítimos para combatir al virus cuanto invisible enemigo, como lo hace ver "El coronavirus como declaración de guerra" de Santiago López Petit quien afirma, además, que hay una estrecha interrelación entre la agroindustria capitalista y la etiología de las epidemias recientes donde el capitalismo sin contrapesos produce el virus que él mismo reutiliza, más tarde, para controlarnos en escenarios propios de la guerra.

Otro campo geopolítico que visita La sopa de Wuhan es el de las resistencias y las alternativas frente al capitalismo como forma de vida y la situación en la que se encuentra dentro de esta la "pausa social" en la que se han visto sumidos miles de ciudadanos y ciudadanas en todo el mundo. Slavoj ŽiŽek habla, metafóricamente, en "El coronavirus es un golpe al capitalismo a lo Kill Bill...", de epidemias y de virus ideológicos, latentes en nuestras sociedades: noticias falsas, teorías de conspiración paranoicas, explosiones de racismo, pero también hay otro virus ideológico, que lleva 
latente una sociedad alternativa, más allá del estado-nación, que se actualiza a sí misma en las formas de solidaridad y cooperación global, que replantea al comunismo. A partir del contraste de la eficacia para la gestión del coronavirus entre Asia y Europa, el artículo "La emergencia viral y el mundo de mañana", de Byung-Chul Han reconoce que el manejo alternativo de la pandemia está en la digitalización. Lo cual obliga, incluso, a redefinir la soberanía personal y nacional. Si ya en los tiempos de la guerra fría, la sociedad organizada inmunológicamente vivía acotada por fronteras y vallas nacionales, hoy las alternativas son desafiadas por los modos de gestión que se hacen en sociedades culturalmente diferenciadas.

¿Qué escenarios alternativos de corte anticapitalista ofrece la pandemia del coronavirus? Desde una visión neta de la geopolítica crítica, el trabajo "Política anticapitalista en tiempos de coronavirus", de David Harvey plantea dos modalidades capitalistas que condicionan y determinan el sentido de la crisis sanitaria de la Covid-19. Una, se refiere a la incesante necesidad de acumulación que propicia el capital financiero, con sus rivalidades geopolíticas, desiguales desarrollos geográficos, institucionales, tecnológicos y la siempre cambiante división internacional del trabajo, donde las regulaciones públicas estatales están sesgadas para favorecer al capital. La otra modalidad que contrapone Harvey es la formación social distintiva del capitalismo, donde se anidan alternativas globales y diferenciadas en la geografía desigual del capitalismo.

China reforzó su poder global al mostrar sus dispositivos para enfrentar la crisis sanitaria y la pronta reestructuración económica a través del control social de la población mediante políticas de Estado, así lo dice en su artículo Raúl Zibechi: "A las puertas de un nuevo orden mundial". Las coordenadas caóticas del Sistema Mundo que heredó el capitalismo global corporativo están cimbrando las tendencias dominantes en curso, que se aceleran en la coyuntura pandémica: militarización, declive hegemónico de Estados Unidos y ascenso de Asia Pacífico, deterioro del poder europeo, fin de la globalización neoliberal corporativa, reforzamiento de los Estados y auge de las ultraderechas.

Si bien el enfoque de género se encuentra presente en varios trabajos de la Sopa de Wuhan, hay algunos que tienen como eje el debate feminista y de género. En "El capitalismo tiene sus límites" de Judith Butler se constata la incapacidad para anticiparse a la pandemia de algunos estados o regiones, resaltando Estados Unidos, junto con el oportunismo de empresarios ansiosos por capitalizar el sufrimiento global. Así, el refuerzo de las políticas nacionales y el cierre de las fronteras, frecuentemente, fomentan desigualdades sociales, étnicas y económicas que se fundan sobre nacionalismos excluyentes, la supremacía blanca y patriarcal con sus muestras de violencia contra las mujeres y las personas LGBTTTIQ, donde la explotación capitalista encuentra formas de reproducir y fortalecer sus poderes dentro de las zonas pandémicas. "Aprendiendo del virus", de Paul B. Preciado toma la idea foucaltiana de poder. Pues la acción política estatal y sistémica en general es fabricar un cuerpo, adaptarlo al trabajo, acotar sus modos de reproducción. Podríamos aquí encontrar un discurso biopolítico y geopolítico que está destinado a individualizar al cuerpo en el "yo", aunque ese ego sea ficción. Una obra responsabilidad del Estado nacional patriarcal que invisibiliza y criminaliza la diferencia de manera acentuada en época de pandemia.

La transformación estética en tiempos del coronavirus expresa con nitidez la diferencia entre las pulsiones de la vida y de la muerte, pero les da una escala planetaria al reconocer una dimensión psicológica que es universal. "Crónica de la psicodeflación", de Franco "Bifo" Berardi recurre a una narrativa de la cotidianeidad sobre su percepción del grado de irritación que ha alcanzado 'La Tierra' -síntesis entre naturaleza y sociedad planetaria- donde el cuerpo colectivo de la sociedad viene padeciendo un estado de stress intolerable. Incertidumbre inmunitaria que hace que 
"lo ignoto de repente detiene la máquina. Un virus semiótico en la psicósfera bloquea el funcionamiento abstracto de la economía, porque sustrae de ella los cuerpos." (p. 37) Tomando distancia de la urgencia de la coyuntura que tiene el riesgo de simplificar nuestro conocimiento, el trabajo "Hospitalidad e inmunidad virtuosa", de Patricia Manrique adopta a Lévinas quien llama hospitalidad a la acogida de la otredad, al rostro del otro, a la apertura frente a la vulnerabilidad que moviliza, que invita al diferente, lo cual confronta esa responsabilidad que atañe al yo en la forma de una cierta pasividad, de inhibición, de evitar, a su juicio, la derivación hacia la violencia 'hospitalaria'.

\section{La Fiebre: geopolítica crítica desde el Sur Global}

Así como la Sopa de Wuhan canalizó inquietudes intelectuales principalmente anglo-eurocéntricas, el fenómeno del intelectual colectivo que investiga y piensa en clave geopolítica amplía sus horizontes hacia las instituciones de educación superior del Norte, donde destaca el caso de la Johns Hopkins University. En el Sur del mundo también hay compromisos intelectuales en las instituciones educativas, donde están los ejemplos de la Asociaçao Nacional de PostGraduaçao e Pesquisa em Ciencias Sociais (ANPOCS) de Brasil y del Consejo Latinoamericano de Ciencias Sociales (CLACSO), espacios académicos desde los que se fomenta un estudio interdisciplinario que se relaciona con el campo problemático de la geopolítica crítica.

Algo similar acontece con las principales empresas de los medios de difusión en la inmensa mayoría de países afectados por altos niveles de contagio y muerte por coronavirus, donde el pensamiento geopolítico contribuye a una problematización integral compleja de la pandemia. Así lo muestran los mapas interactivos on-line y en tiempo real con actualización permanente de datos, que son preciadas herramientas para la investigación sobre la multidimensionalidad de la crisis sanitaria. Fuentes de información potentes que dinamizan al mundo de las redes sociales, desde donde se amplifica la difusión de imaginarios geopolíticos encontrados, confrontados, alrededor de los cuales se producen complicados clivajes políticos y culturales con narrativas contradictorias sobre el espacio y tiempo del coronavirus, sus impactos y la prospectiva sobre el futuro, si es que se considera su pertinencia.

Otro ejemplo de producción intelectual en el que converge el pensamiento crítico y la influencia geopolítica de la Covid-19 se refleja en el libro La Fiebre (Pensamiento contemporáneo en tiempos de pandemias), compilado por Maristella Svampa. El libro gira en torno a la Covid-19 u otras pandemias y su impacto sociopolítico, y el reto que representa como una enfermedad zoonótica. En este, Mónica B. Cragnolini señala que "las zoonosis, como su nombre lo indica, remiten a aquellas enfermedades que se transmiten desde animales a humanos" y se remonta a las tres pandemias más grandes por las que hemos transitado (peste negra, gripe española y VIH).

Según la Organización Mundial de la Salud (OMS), la Covid-19 es una enfermedad infecciosa causada por el coronavirus y el primer brote surgió en diciembre de 2019. La Covid-19 de ser una pequeña enfermedad local en Wuhan, capital de la provincia de Hubei, el territorio más poblado de China se transformó en una de las enfermedades históricas del planeta en lo que va del Siglo XXI. La evolución del virus en una epidemia y posteriormente una pandemia fue declarada el 11 de marzo del 2020 a través de un tuit de la cuenta oficial de la OMS².

Hablar de coronavirus es hablar de sistemas de salud en materia geopolítica. Y, como esta pandemia hizo notar, existen muchas diferencias entre los avances médicos y de infraestructura hospitalaria en los países donde se han presentado casos de contagio, lo cual conforma y confirma terribles geografías de la desigualdad. El número de camas en hospitales y la disponibilidad de Unidades de Cuidados Intensivos (UCI) o

2 https://twitter.com/WHO/status/1237777021742338049 
de respiradores por país es contrastante: mientras Japón tiene 1350 camas por cada 100 mil habitantes, Bolivia tiene 110. Si se incluyen camas públicas y privadas, Alemania cuenta con 33 unidades de cuidados intensivos por cada 100 mil habitantes. Le sigue Estados Unidos con 30, Perú tiene 1. Aunque China tenía en marzo de 2020 tan solo una ratio de 4 camas, sus UCI no se vieron sometidas a tanta presión como las de España que tiene 9 o Italia cuyas camas para UCI, eran 8 por cada 100 mil habitantes ${ }^{3}$.

Las geografías desiguales se acentúan cuando cambiamos de escala. Por ejemplo, el $60 \%$ de los municipios brasileños, donde habitan más de 33 millones de personas no cuentan con respiradores. Esos municipios se concentran principalmente en las regiones norte y nordeste de Brasil ${ }^{4}$.

Esta enfermedad comenzó a propagarse en los territorios, sin abandonar China, a Italia, España e Irán siendo estos los principales países afectados y con mayor número de casos de infecciones y mortalidad, hasta inicios de mayo de 2020. Sin embargo, y como lo vemos en La fiebre, la distribución de la Covid-19 ha dado una vuelta inesperada. Desde mediados de junio, los países que representan el mayor riesgo se encuentran en el continente americano siendo estos: Estados Unidos de América, México y Brasil los países con mayor población y territorio en el continente. Estados Unidos de América representa el 49\% y Brasil representa el 27\% de todos los casos, y este último representa el $24 \%$ de todas las muertes en el territorio latinoamericano. La sumatoria de ambos países representa el 76\% de todos los casos y el $73 \%$ de todas las muertes reportadas en el continente americano (al 10 de julio de 2020).

Entre muchas otras invitaciones a reflexionar sobre cómo hemos sobrellevado la pandemia mediante el aislamiento, y las medidas desplegadas ante la Covid-19, Ariel Petruccelli y Federico Mare se plantean en el libro La Fiebre: "¿habría tanto terror mortis frente al coronavirus si este fuese una típica enfermedad de la pobreza y la periferia, como el cólera o el paludismo, que causan estragos mucho mayores?" A lo que enseguida responden "Italia no es Mozambique o Haití, ni España es Camboya o Nicaragua; y las clases altas y medias que pueden cultivar el turismo internacional o los viajes de negocios, llevando o trayendo el coronavirus, nada tienen que ver con el «pobrerío oscuro» que habita en zonas rurales y urbano-marginales del planeta. Hay vidas que valen más que otras, conforme a criterios de clase y "étnico-geopolíticos". Este escenario se replica en los países considerados tercermundistas, donde el impacto económico sobrepasa los impactos de la salud, ya que importa más el mercado que la salud y la vida.

Existe una producción constante de estudios y análisis respecto de esta pandemia, sus resultados los escuchamos o los vemos día tras día, y frecuentemente son abrumadores. Nos asaltan las cifras actualizadas al día sobre el aumento de casos y decesos por Covid-19, al mismo tiempo que se incrementan teorías sobre la conspiración mundial y en donde ganan cada vez mayor espacio las falsas noticias. En los mitos conspirativos, una parte de la sociedad considera que esas cifras son patrañas, aunque la realidad es tan abrumadora y palpable, que no es fácil ignorarla. Esto lo desarrolla Petruccelli (AA.VV. 2020A: 121) en su artículo La política del terror, en el libro La Fiebre: "sucede que las falsas noticias suelen ser espectaculares, las verdaderas no. Y los sujetos de la sociedad del espectáculo buscan lo espectacular y creen en lo espectacular."

Sin duda que el lugar ha sido el gran tema capturado por la pandemia del coronavirus. Aun cuando uno quisiera ser ajeno a los hechos, no se puede dejar de lado la idea de vivir y el sentido diferenciado de los lugares en la supuesta "nueva normalidad", donde los jefes y el ámbito de trabajo transgreden la casa propia y tu casa se vuelve tu oficina. ¿Cuán saludable es esto? Como señala María Pía López: "la cuarentena 3 El Orden Mundial, disponible en: https://elordenmundial.com/mapas/cuantas-camas-uci-tiene-cada-pais/ 4 UOL-Brasil, disponible en: https://noticias.uol.com.br/saude/ultimas-noticias/redacao/2020/03/20/coronavirus-60-das-cidades-nao-tem-respiradores-para-enfrentar-epidemia.htm?cmpid=copiaecola 
empezó a ser un privilegio accesible a quienes tenemos lugar para encerrarnos y un salario, aunque no salgamos a trabajar." Esto se sobrepone a la crisis que enfrenta, según Candelaria Botto, "el 99\% de la población [que] vive la pandemia con angustia ante la incertidumbre del qué pasará, muchos habiendo perdido sus trabajos y otros tantos de forma hacinada, [mientras que el] grupo selecto de la humanidad... se fue a vivir la cuarentena alejados del mundo, con el servicio doméstico que vive en una modalidad que se asemeja a una esclavitud moderna".

Varios autores de La Fiebre, no fallan en señalar cómo en la región de América Latina, Argentina es el ejemplo de la política más dura en aislamiento y medidas drásticas respecto de la prevención de contagios de Covid-19 aludiendo sin embargo, como señala Maristella Svampa a esta "asociación entre discurso bélico y la figura del «ciudadano policía», erigido en atento vigía, dispuesto a denunciar a su vecino al menor desliz en la cuarentena."

María Pia López aborda el tema del orden y control social en su artículo la vida en cuestión, donde plantea que "En situación de pandemia, prima la idea de un orden necesario: el aislamiento obligatorio exige la voluntad ciudadana de acatarlo, pero también el control policial de la circulación. Las libertades individuales son suspendidas en nombre del bien común." Esto nos transporta al escenario imaginario que George Orwell había descrito en su novela 1984. Tal como lo señala en su artículo Giorgio Agamben "Una sociedad que vive en un estado de emergencia permanente no puede ser una sociedad libre."

\section{Geopolítica crítica desde la academia latinoamericana}

Como ya se había señalado antes, dentro de los espacios académicos desde los que se fomenta un estudio interdisciplinario que contribuye al campo problemático de la geopolítica crítica y la relación con la Covid-19, se suman a la producción científica sobre el coronavirus algunas instituciones que han destinado parte de su presupuesto financiero como su capital intelectual, a la creación de espacios para el análisis de esta pandemia.

Un claro ejemplo de esto es la Biblioteca en acceso abierto Pensar la Pandemia. Observatorio Social del Coronavirus, de CLACSO el cual se ha enfocado en publicar una agenda temática diversa en las disciplinas que se expresan y en el origen continental de las y los autores. Los artículos se publican bajo la edición de un dossier titulado "Pensar la pandemia. Observatorio Social del Coronavirus" del cual el primer número fue publicado en mayo de 2020 y el último número consultado fue el número 77 correspondiente a julio de 2020. En el Anexo 1, se incluyen artículos, fechas, autorxs, a partir de una búsqueda que facilita la página Web de CLACSO, pues dentro de las etiquetas de palabras clave incluye: "Geopolítica y asuntos de interés internacional". Gracias a ello se encontró una riqueza y variedad temática que muestra la vitalidad y resultados que ofrece la academia enfocada desde una epistemología del Sur Global ${ }^{5}$.

En Brasil, varias organizaciones del país: instituciones de educación superior, universidades, dependencias federales y de los estados federados, se unieron para crear el boletín "Cientistas sociais e o coronavirus", una iniciativa liderada por la Associação Nacional de Pós-Graduação e Pesquisa em Ciências Sociais (Anpocs) la cual reúne más de 70 organizaciones, instituciones y asociaciones científicas sociales brasileñas, las cuales han publicado desde el día 22 de marzo de 2020 hasta el día 15 de julio de 2020 una cantidad de 83 boletines.

En el Anexo 2 se puede apreciar lo acertado de las políticas interinstitucionales con la finalidad de crear sinergias entre las y los investigadores en temas pertinentes

5 Escapa a los objetivos de este trabajo el hacer un análisis pormenorizado sobre los contenidos temáticos de cada artículo incluido en dos Anexos al final del trabajo. Los que incluimos con la finalidad de compartir estos hallazgos para futuras investigaciones. 
que ponen al servicio de la comunidad académica, de las instituciones y de los actores sociales. Empero, Los boletines no tienen etiquetas con palabras clave para la búsqueda. En el Anexo 2 se puede constatar que no hay artículos que contengan la palabra geopolítica en sus títulos, aunque si hay una amplia variedad temática si se analiza el contenido siguiendo la afinidad de conceptos geopolíticos, de acuerdo con ciertas palabras clave como: geografía, territorio, poder, gobierno, necropolítica. Queda, no obstante, la inquietud sobre la ausencia de referencias explícitas a la palabra geopolítica. Quizá el origen militarista de este concepto, asociado con las traumáticas experiencias de la dictadura en el Cono Sur, ahuyente enfoques que están superando a la geopolítica clásica, desde una mirada crítica.

Los boletines son textos publicado semanalmente, entre los principales colaboradores se encuentran la Sociedade Brasileira de Sociologia (SBS), la Associação Brasileira de Antropologia (ABA), la Associação Brasileira de Ciência Política (ABCP), la Associação dos Cientistas Sociais da Religião do Mercosul (ACSRM) la Sociedade Brasileira para o Progresso da Ciência (SBPC/SC), la Associação Nacional de PósGraduação em Geografia (ANPEGE), la Associação Nacional de Pós-Graduação em História (ANPUH), la Associação Nacional de Pós graduação e Pesquisa em Letras e Linguística (Anpoll) y la Associação Nacional de Pós-Graduação e Pesquisa em Planejamento Urbano e Regional (Anpur). Esta convergencia interdisciplinaria ha propiciado una respuesta diversificada ante la pandemia de la Covid-19, a través de la cual se aportan conocimientos pertinentes para mejor comprender y actuar desde el Estado, la sociedad, el régimen político y el sistema de actores.

La Comunidad de Estados Latinoamericanos y Caribeños (CELAC) por su parte, es de las pocas instancias multilaterales que permanecen activas ya que aportará recursos y conocimientos a la iniciativa Cumbre de Respuesta Global (Global Response), impulsada por la Unión Europea, para enfrentar la pandemia generada por la Covid-19. La CELAC generó un buscador focalizado con la palabra pandemia, el cual ofrece toda la información relacionada con esta enfermedad, desde noticias, artículos, foros de debate etc.

La CELAC, junto con la CEPAL, organizaron el 28 de mayo de 2020 la reunión virtual "Hacia una Nueva Economía Global: Encuentro Universitario-Ministerial" (Xinhua, disponible en: http://spanish.xinhuanet.com/2020-05/29/c_139097935.htm). Ahí se propuso promover el desarrollo tecnológico y científico en la región para tender a la autosuficiencia sanitaria y vincular a fabricantes de equipo médico con las investigaciones para encontrar la vacuna contra la Covid-19. Se recomendó que gobiernos, sociedad civil y universidades trabajen coordinados en el diseño de un nuevo modelo de desarrollo basado en la cooperación entre Estados y el fortalecimiento del multilateralismo en la región. Igualmente, la Unión de Universidades de América Latina y el Caribe (Udual), presentó un estudio sobre los desafíos en la región ante la pandemia y las medidas que los miembros de la CELAC han implementado. La CEPAL presentó el "Informe sobre el impacto económico en América Latina y el Caribe de la enfermedad por el nuevo coronavirus (Covid-19)", elaborado a petición de la presidencia mexicana pro tempore de la CELAC, pues la pandemia generará recesión y aumento del desempleo en la región.

\section{Conclusiones}

Diversos enfoques de la geopolítica crítica se posicionan en el debate público informado sobre la singularidad de la crisis global, sistémica, planetaria, donde la pandemia de la Covid-19 comprime el espacio-tiempo dentro de una simultaneidad on-line que nos hace ser contemporáneos. En parte intencionalmente, pero también gracias al impacto espontáneo, ese concepto muestra su pertinencia entre la opinión pública, entre los expertos profesionales que piensan en la relación entre espacio 
y poder, y entre los operadores políticos estatales y no estatales, cuyas prácticas socioespaciales están vinculadas con la transformación del territorio.

Las exigencias interpretativas de la pandemia del coronavirus propician nuevas convergencias inter y transdisciplinarias, que propician síntesis creativas que contribuyen a unir lo que en nuestro conocimiento aparece como fragmentado, lo cual refuerza aproximaciones holísticas que interrelacionan el todo y las partes bajo principios que son, a la vez, dialógicos, recursivos y de auto-eco-organización. Una teoría de la complejidad, propuesta por Edgar Morin, que refuerza el juego de escalas propio de la geopolítica.

La Covid-19 nos sitúa en el origen común de nuestra especie: la permanente batalla entre vida y muerte. De la misma manera nos lleva a preguntarnos sobre el sentido que rige la actual dirección común: nadie está a salvo, si queda tan solo un enfermo que reproduzca el virus.

La pandemia de la Covid-19 está politizada en un espacio y territorios politizados. La reflexividad que el contagio viral exige se da en contextos relacionales entre el Sistema Mundo Moderno y el orden mundial heredado; entre la globalización y la localización de actividades humanas que se vinculan entre sí y que se adaptan o resisten las formaciones socioeconómicas, sociopolíticas o socioculturales dentro de su diversidad, su desigualdad y su particularidad geográfica ambiental. Sobre todo, el coronavirus politiza la escala del Estado-nación. Ese en que la globalización del mercado a ultranza desecha en su discurso por oponerse a la libre circulación de mercancías y de capitales -la que regula desde el Estado la circulación restringida de migrantes-, pero que lo instrumentaliza como el pivote para socializar las pérdidas y privatizar las ganancias.

Las modalidades para gestionar el combate -algunos dirían la guerra- contra la pandemia más rápidamente contagiosa y letal que las precedentes, politiza al estado nacional al convertirlo en la escala privilegiada desde donde se puede contener la pandemia. El Estado de excepción y el Estado de sitio coronan las formas de control sobre las fronteras, sobre la regulación de los flujos de interconectividad ligados con las cadenas de suministro, sobre la movilidad y el confinamiento de las personas.

Si bien hay gestiones sanitarias diferenciadas geográficamente respecto del uso de dispositivos como las pruebas masivas, los equipamientos médicos y en la gradualidad del confinamiento y distanciamiento social, el desmantelamiento previo a la pandemia del sistema de salud, el debilitamiento de las políticas sociales en la procuración de bienes públicos no mercantiles o políticas económicas orientadas por el productivismo y la exportación hacia mercados globales, heredan una geografía diferenciada en sus regímenes de acumulación, de reproducción del orden social y político. Más que un interregno, donde la incertidumbre y el caos se debaten entre lo viejo que muere y lo vivo que lo reemplaza, estamos ante el (re)surgimiento de imaginarios geopolíticos que actualizan aquella consigna del Foro Social Mundial en 2001: "Otro mundo [de particularismos universalistas, mejor que el actual] es posible".

Pese a la tragedia que significan la letalidad y las muertes que se ha cobrado la Covid-19, coincidimos con Maristella Svampa (AA. VV. 2020 A: 28) “lo peor que podría ocurrir es que nos quedemos en casa convencidos de que las cartas están marcadas y que ello nos lleve a la inacción o a la parálisis, pensando que de nada sirve tratar de influir en los procesos sociales y políticos que se abren, así como en las agendas públicas que se están instalando." Y, también, coincidir con Silvia Ribeiro (AA. VV 2020: 48): "la guerra la iniciamos nosotros cuando creímos que todo lo viviente estaba a nuestro servicio, allí, «a la mano», listo para ser utilizado, manufacturado, consumido, aniquilado mientras supuestamente se trabaja para contenerlo, otros virus y pandemias se siguen formando." 


\section{Referencias Bibliográficas}

AA. VV (2020). Sopa de Wuhan, Pensamiento contemporáneo en tiempos de Pandemias. Universidad Católica Argentina, Facultad de Teología. Argentina. Disponible en: https://repositorio. uca.edu.ar/handle/123456789/10038

AA. VV (2020a). La fiebre. Pensamiento contemporáneo en tiempo de pandemia. ASPO (Aislamiento Social Preventivo y Obligatorio). Argentina. Disponible en: https://www.elextremosur. com/files/content/23/23821/la-fiebre-aspo.pdf

Agnew, John (2016). "The origins of Critical Geopolitics", en Dodd, Klaus; Merjee Kuus and Joanne P. Sharp: The Routledge Research Companion to Critical Geopolitics, pp. 19-33. Routledge, London and New York.

Barrios, Miguel Ángel (2009). Diccionario latinoamericano de seguridad y geopolítica. Biblos, Argentina.

Borón, Atilio (2012). América Latina en la geopolítica del imperialismo. Ediciones Luxemburg, Argentina.

Cairo Carou, Heriberto (1993). “Elementos para una geopolítica crítica: tradición y cambio en una disciplina maldita". ERÍA Revista cuatrimestral de Geografía, pp. 195-213, Asturias.

Chaturvedi, Sanjay y Timothy Doyle (2015). Climate Terror: A Critical Geopolitics of Climate Change. New Security Challenges. Palgrave Macmilla,. UK.

Ceceña, Ana Esther; Yedra, Rodrigo y Barrios, David (2009). Un continente bajo amenaza: el águila despliega sus alas de nuevo. Geopolítica de la Dominación y la Emancipación. Observatorio Latinoamericano de Geopolítica. Fedaeps, México.

Dalby, Simon (1991). "Critical Geopolitics: Discourse, Difference, and Dissent". Environment and Planning D: Society and Space, 9(3), pp. 261-283. https://doi.org/10.1068/d090261

Dodds, Klaus (2000). Geopolitics in a changing world. Harlow, England New York: Pearson Education

Mies, María y Vandana Shiva (2016). Ecofeminismo. Icaria, España

Montanaro Mena, Ana Marcela (2017). Una mirada al feminismo decolonial en América Latina. DYKINSON, S.L. Madrid.

Ó Tuathail, Gearóid (1996). Critical Geopolitics. The Politics of Writing Global Space. Routledge, London.

Routledge, Paul; Joanne P. Sharp; Chris, Philo and Ronan Paddison (2000). Entanglements of Power:Geographies of Domination / Resistances. Routledge, London and New York.

P. Sharp, Joanne (1993). “Hegemony, Popular Culture and Geopolitics: The Reader's Digest and the Construction of Danger". Political Geography, N 15 (6-7) pp. 550-570.

Thiong'o, Ngugi wa (2015). Descolonizar la mente. DeBolsillo, España. 


\section{ANEXO 1}

\section{CLACSO: Pensar la pandemia. Observatorio Social del Coronavirus}

\section{ARTÍCULOS}

\section{Artículos que mencionan contenidos geopolíticos en su título Nombre del artículo / Temas geopolíticos}

La pandemia como crisis ecopolítica. Desafíos de investigación 16 junio 2020, Gabriela Merlinsky

A faceta espacial do neoliberalismo e a Pandemia na América Latina, 1 junio 2020 Grupo de Trabalho Pensamento Crítico Latino-Americano

Covid-19 y crisis del petróleo: una oportunidad para repensar la matriz energética, 11 mayo 2020, Agustina Sol Sánchez

China y el nuevo momento geopolítico mundial, 4 mayo 2020, Gabriel E. Merino El mundo después del coronavirus y la reorganización del capitalismo fósil, 4 mayo 2020, Maritza Islas Vargas

Covid-19: Catalizador de la crisis mundial y el nuevo papel de China, 28 abril 2020, Grupo de Trabajo CLACSO China y el mapa de poder mundial

Lecciones desde la emergencia: entre el coronavirus y el cambio climático, 28 abril 2020, Maritza Islas Vargas

Coronavírus e biopolítica neoliberal, 27 abril 2020, Luís Gustavo Guerreiro Moreira La crisis económica global del "coronavirus" y América Latina, 22 abril 2020, Arturo Guillén

Riesgos globales en sistemas en declive. A propósito de la Covid-19, 20 abril 2020, Nivaria Ortega Monche

Interdependencia de la vida humana / no-humana: Covid-19 e hipótesis en disputa, 14 abril 2020, Mina Lorena Navarro

El militarismo de los Estados Unidos en tiempos del Coronavirus, 13 abril 2020, Leyde Ernesto Rodríguez Hernández

Poscoronavirus: El mundo que resultará de todo esto, 13 abril 2020, Gerardo Pisarello

Reflexiones para un mundo post-coronavirus, 8 abril 2020, Maristella Svampa

Geopolítica energética de Estados Unidos en Nuestra América, 8 abril 2020, Aníbal García Fernández

Acusaciones y medidas criminales contra Venezuela en épocas de pandemia, 7 abril 2020, Pasqualina Curcio Curcio

¡No es el coronavirus, estúpido! Es una nueva fase de la crisis del capital, 7 abril 2020, Arturo Guillén

La pandemia Covid-19 agrava la crisis capitalista, 6 abril 2020, Julio C. Gambina La pandemia y el fin de la era neoliberal, 29 marzo 2020, Atilio A. Borón La crisis del capitalismo y el coronavirus, 25 marzo 2020, Marco A. Gandásegui hijo 
2 Artículos que incluyen explícitamente contenidos geopolíticos en su texto Nombre del artículo / Temas geopolíticos

Coronavirus: Rebrotes y restricciones en el mundo. Nadie se contagia solo, 29 junio 2020, Manuel Valenti Randi

La cuarentena de las ideas, 23 junio 2020, Nicolás Lynch

Covid-19 y el nuevo caos global 19 junio 2020, Breno Bringel

Pandemia, coronavírus e Dogville 18 junio 2020, Jamile Borges da Silva

La pandemia, un sueño que agoniza y la vuelta al Estado de bienestar, 8 junio 2020, Dídimo Castillo Fernández

Impactos del COVID en el empleo: una perspectiva comparada, 2 junio 2020, Matías Lioni

China adapta su plan ante la nueva situación, 28 mayo 2020, Augusto Soto

El Equipo Argentino de Antropología Forense frente a la pandemia, 18 mayo 2020, El EAAF, candidato al Nobel de la Paz

Emergencia: sociedad, ambiente y economía. Una oportunidad para la TSE, 13 mayo 2020, Antonio de Lisio

Corona-crisis y libre comercio, 7 mayo 2020, Luciana Ghiotto

"La Bolsa o la Vida" - Invertir la mirada de lo privado y lo público,6 mayo 2020, Alain Basail Rodríguez

Miedo, mentiras, conspiración y pandemia, 5 mayo 2020, Lina Luna

La revisión china de las cifras del Covid-19, 5 mayo 2020, Guillermo Puyana Ramos

Los nuevos comienzos y la educación. Reflexiones desde el confinamiento, 4 mayo 2020, Freddy Javier Álvarez González

Un Mercosur en cuarentena, 30 abril 2020, Tomás Bontempo

Oportunidades y desafíos para América Latina y el Caribe durante y después de la pandemia, 25 abril 2020, El Ministerio de Educación de Argentina y organizaciones científicas internacionales

Experiencia inédita. Covid-19, 23 abril 2020, Clara Schor Landman

El coronavirus desenmascara la posverdad, 23 abril 2020, Alejandro Pelfini

Covid-19 (I): La autoconservación social, 21 abril 2020, Esteban Torres

Evocación en medio de las crisis socioeconómicas y sanitarias (sobre Edgardo Lifschitz), 20 abril 2020, Carlos Fidel

O Brasil, o governo Bolsonaro e os desafios da Covid-19, 14 abril 2020, Ivandilson Miranda Silva

La razón científica frente al populismo en tiempos de coronavirus, 26 marzo 2020, Julio Solís Moreira

La pandemia no será impune para la sociedad, 24 marzo 2020, Gerónimo de Sierra

Artículos que contienen la etiqueta "Geopolítica y situación internacional", búsqueda en: https://www.clacso.org/?search=pandemia\&s\&categoria temas $\% 5 \mathrm{~B} 0 \% 5 \mathrm{D}=1397 \&$ categoria_formatos $\% 5 \mathrm{~B} 0 \% 5 \mathrm{D}=1279$ 


\section{ANEXO 2}

ANPOCS: Boletim, Cientistas sociais e o coronavírus (21 artículos)

1 Artículos que mencionan contenidos geopolíticos en su título Nombre del artículo / Temas geopolíticos

NO HAY

2. Artículos que incluyen explícitamente contenidos geopolíticos en su texto Nombre del artículo / Temas geopolíticos

Boletim n. 79 | Um mundo de ponta-cabeça? O "novo normal" pós-pandemia, Por Bruno Lucas Saliba de Paula e Victor José Alves Fernandes Publicado em 08/07/2020

Boletim n. 77 | CONSTITUCIONALIDADE versus INSTITUCIONALIDADE: Direitos territoriais quilombolas em tempos de Covid-19, Por Kelly dos Santos Araújo e César Augusto Danelli Jr. Publicado em 06/07/2020

Boletim n. 68 | Quando a Covid-19 chega aos CAPSad: usuários de drogas, saúde mental e SUS no Rio de Janeiro, Por Beatriz Brandão Publicado em 23/06/2020

Boletim n. 66 | Imigrantes, refugiados e o coronavírus: notas para reflexão, Por Alexandre Branco Pereira Publicado em 19/06/2020

Pandemia, necropolítica e purificação simbólica dos cuidadores da morte Por Welliton Caixeta Maciel, Publicado em 19/06/2020

Boletim n. 54 | Covid-19, espaçamento social e o mundo por vir: a Reforma Agrária como parte da solução, Por Thiago Lima Publicado em 03/06/2020

Boletim n. 42 | Um panorama sobre os grupos Ciganos e a Covid-19 no território brasileiro, Por Cleiton M. Maia e Edilma do Nascimento J. Monteiro Publicado em 18/05/2020

Os ribeirinhos e o novo coronavírus, Por Cristiane Montalvão Guedes, Publicado em $18 / 05 / 2020$

Boletim n. 40 | Território e Vida Mental: Notas sobre o "mundo pós Covid-19" do lado de cá do planeta, Por Pedro Henrique Campello Torres Publicado em $14 / 05 / 2020$

Boletim n. 17 Desterritorialização sem limites. Reflexões geográficas em tempos de pandemia, Por Rogério Haesbaert, publicado em 09/04/2020

Boletim n. 15 | A gestão da pandemia do Coronavírus (Covid 19) no Brasil e a necropolítica: um ensaio sobre uma tragédia anunciada, Por Daniel Granada, publicado em 07/04/2020

Boletim n. 6 | A produção do social em tempos de pandemia, Por grupo de pesquisa Tecnologia, Meio Ambiente e Sociedade - TEMAS - publicado em 27/03/2020

Boletim n. 5 | Medo Global, Por Gustavo Lins Ribeiro- publicado em 26/03/2020

Boletim n. 2 Covid-19: escalas da pandemia e escalas da antropologia Por Jean Segata - publicado em 23/03/2020 


\section{Artículos que aluden a lo geopolítico sin nombrarlo Nombre del artículo/ Temas geopolíticos}

Boletim n. 76 | Publicado em 03/07/2020

O enfrentamento da pandemia na África: algumas lições, Por Juliana Braz Dias

"O nosso tempo é o tempo da urgência": Os impactos da pandemia de Covid-19 em duas Residências Terapêuticas na Zona Norte do Rio de Janeiro, Por Monique Torres

Boletim n. 71 | A relação entre distanciamento social e violência doméstica durante a pandemia: o contexto do Piauí, Por Rossana Maria Marinho Albuquerque e João Marcelo Brasileiro de Aguiar Publicado em 26/06/2020 O Covid-19 e o reconhecimento do trabalho doméstico como essencial, Por Michelle Franco Redondo, Publicado em 26/06/2020

Boletim n. 61 | Publicado em 12/06/2020

Não estamos em Guerra! A retórica belicista no enfrentamento ao Covid-19, Por Gabriel Fernandes Caetano

Conexões íntimas e corporalidades singulares: deficiência em tempos de pandemia da Covid-19, Por Helena Fietz, Anahí Guedes de Mello e Claudia Fonseca

Boletim n. 44 | As mulheres negras e a pandemia do coronavírus, Por Viviane Gonçalves Freitas Publicado em 20/05/2020

Covid-19nas prisões brasileiras: seletividade penale produção de corpos descartáveis Por Kátia Sento Sé Mello Publicado em 20/05/2020

Boletim n. 38 | Os governos municipais frente ao Coronavírus, Por Marta Mendes da Rocha (NEPOL/UFJF) Publicado em 12/05/2020

Boletim n. 28 | Covid e mineração - a crise como o contexto e o lucro como necessidade, Por Rafael Lopo Publicado em 27/04/2020

Boletim n. 23 | Policiamentos em Tempo de Coronavírus. Relatos da ação e observação, Por Susana Durão, publicado em 17/04/2020

Boletim n. $10 \mid$ Violências contra mulheres em tempos de Covid-19, Por Patrícia Rosalba Salvador Moura Costa, publicado em 01/04/2020

Boletim n. 4 Contenção de crises no Brasil e seus reflexos no mundo do trabalho sob as lentes da sociologia, Por Maurício Rombaldi - publicado em 25/03/2020

Búsqueda de palabras clave: geografía, territorio, poder, gobierno, necropolítica, disponible en: http://www.anpocs.com/index.php/ciencias-sociais/destaques/2753publicacoes/boletim-cientistas-sociais/2325-boletim-semanal 
